\title{
Soft tissue infection caused by Streptococcus dysgalactiae subsp. equisimilis possessing group A antigen: a case report and review of the literature
}

\author{
Michał Karyński ${ }^{1}$, Iwona Łętowska', Paweł Grzesiowski² \\ ${ }^{1}$ National Medicines Institute, Warsaw, Poland \\ Head: Prof. Zbigniew E. Fijatek \\ 2The Prevention of Infection Institute, Warsaw, Poland \\ Head: Dr Paweł Grzesiowski
}

Postep Derm Alergol 2012; XXIX, 4: 330-336 DOI: $10.5114 /$ pdia.2012.30476

\begin{abstract}
The study presents microbiological characteristics, identification, pathogenicity, epidemiology and antimicrobial susceptibility of Streptococcus dysgalactiae subsp. equisimilis (SDSE). The SDSE shows a close relationship to Streptococcus pyogenes. The SDSE strains usually have a group $\mathrm{G}$ antigen, less commonly a group C one. Like S. pyogenes, most of SDSE strains can cause complete hemolysis ( $\beta$-hemolysis) on a blood agar medium, and some of them possess the same A type of group-specific cell wall antigen. These common phenotype traits lead to confusion between both species. For this reason, microbiological diagnosis of streptococci should not be finished at the stage of serogrouping. A case of soft tissue infection of the left lower limb of a 30-year-old man is described. The etiological factor of the infection was $\beta$-hemolytic SDSE of group A. Antimicrobial susceptibility tests revealed that the strain is susceptible to penicillin, erythromycin, clindamycin and levofloxacin, while it is resistant to tetracycline. Treatment with first-generation cephalosporin (cefadroxil) was successfully applied, resulting in a complete remission of the infection symptoms.
\end{abstract}

Key words: Streptococcus dysgalactiae subsp. equisimilis, group A streptococci, group C, G, and L streptococci.

\section{Introduction}

Streptococcus dysgalactiae subsp. equisimilis (SDSE) is a taxonomic name, proposed by Vandamme et al., 1996 [1], for $\beta$-hemolytic streptococci isolated from people, possessing group $\mathrm{G}$ or $\mathrm{C}$ cell wall carbohydrate antigens, producing streptokinase active on human plasminogen, and displaying proteolytic activity on human fibrin. Usually SDSE strains have the group $G$ antigen, more rarely the group $\mathrm{C}$ one. According to results of several large investigations (on more than 100 isolates), SDSE isolates with $\mathrm{G}$ antigen consisted from $70 \%$ to more than $90 \%$, and those with C antigen - from $5 \%$ to $26 \%$ of the examined SDSE population [2-8]. The SDSE strains with group A and $L$ antigens are isolated much less frequently [2, 9-16]. In SDSE populations, the participation of strains with group A antigen may amount up to some $3.5 \%[2,17]$, and those with $L$ antigen - up to $0.5 \%[4,6,8]$. Group A antigen is carried by some strains of both SDSE and S. anginosus [18], which is why the term "group A streptococci"
(GAS) should not be treated as synonymous to S. pyogenes. For the same reason, microbiological diagnosis of streptococci should not be finished at the stage of determination of the group antigen.

The SDSE forms large (>0.5 $\mathrm{mm}$ in diameter) grayish colonies surrounded by a wide zone of $\beta$-hemolysis on sheep blood agar, after incubation at $37^{\circ} \mathrm{C}$ in $5 \% \mathrm{CO}_{2}$ atmosphere $[10,19]$. However, some strains are found to induce $\alpha$-hemolysis or no hemolysis at all, in the abovedescribed standard conditions [20-22]. As in the case of S. pyogenes, there exist strains of SDSE which produce oxygen-labile streptolysin O, and no streptolysin S [20, 23, 24]. The occurrence of such strains has been an incentive to search for media and conditions of incubation which would enhance the activity of streptolysin O [20]. Some authors suggest parallel incubation of three plates aerobically, anaerobically and in $5 \% \mathrm{CO}_{2}$ atmosphere [25]. Similarly as with culture test for S. pyogenes [26], it is necessary to stab the inoculated agar with an inoculation loop

Address for correspondence: Michał Karyński MD, National Medicines Institute, 30/34 Chełmska, 00-725 Warsaw, Poland, phone: +48228515203, e-mail: mkarynski@cls.edu.pl 
in order to discover subsurface hemolysis [20]. Due to the occurrence of strains displaying changed hemolytic activity, neither $\alpha$-hemolytic nor nonhemolytic streptococci should be treated as non-pathogenic, especially if they are isolated from patients showing clinical symptoms such as tonsillopharyngitis, rheumatic fever, erythema marginatum, reactive arthritis or glomerulonephritis [25].

\section{Microbiological diagnosis}

The SDSE is most often resistant to bacitracin [2, 9, $18,19]$, but there are also reports on strains susceptible to that antibiotic $[13,14,18,21,27]$. The susceptibility to bacitracin is typical of SDSE strains with a group $L$ antigen [21, 27], but susceptible SDSE isolates with a group A antigen have been described as well $[13,14]$. Typically, SDSE strains produce no L-pyrrolidonyl arylamidase, and display a negative result of the Voges-Proskauer test, positive result of $\beta$-glucuronidase and negative result of $\alpha$ - and $\beta$-galactosidase test $[9,18]$. Most of them do not hydrolyze hippurate, except for SDSE strains with group L antigen [21, 27].

For SDSE identification, the following molecular methods were used: $16 \mathrm{~S}$ rRNA gene sequencing [5, 12, 28-30], polymerase chain reaction (PCR) [15, 28], 23S rRNA gene sequencing [31] and in situ hybridization [29].

The basic methods for genotyping SDSE strains are Multilocus Sequence Typing (MLST), Pulse Field Gel Electrophoresis (PFGE) and emm typing [2, 6-8, 12, 19, 32-34]. About $50 \mathrm{emm}$ types have been described in SDSE so far [6]. It has been observed that different emm types dominate in different geographical regions [19]. Several intercontinental clonal complexes of SDSE have been characterized [6].

\section{Virulence factors and pathogenicity}

The closest species for SDSE is S. pyogenes [35, 36], with sequence similarity at 72\% [35], in spite of the highest similarity with $S$. agalactiae in the $16 \mathrm{~S}$ rRNA gene sequence $[35,37]$. The SDSE has a range of genes showing a high degree of homology with corresponding genes of S. pyogenes. These are, among others, genes encoding different virulence factors such as: fibronectin binding protein, laminin binding protein, streptolysin S, streptolysin $\mathrm{O}$, streptokinase, hemolysin, hyaluronidase, C5a peptidase and C3-degrading proteinase [35]. Both species have antiphagocytic M protein, encoded by emm [10, 35, 36] and hyaluronic capsule $[10,35]$. There are, however, marked differences between them: SDSE, for example, lacks the whole set of genes encoding superantigens, which are mostly of phage origin (spe A, spe $B$, spe $C$, spe $H$, spe I, spe J, spe K, spe L, spe M, ssa, smez) [12, 15, 24, 35, 38-42]. However, scarce occurrences of SDSE strains have been described, having one of those genes [32, 43]. The only superantigen gene which is often found in SDSE strains is spe $G$, which encodes exotoxin $G[12,22,24,32$, $35,36,39-42,44]$. Between both of these closely related bacteria, interspecies DNA transfer occurs $[6,45,46]$ by means of mobile genetic elements.

As a result of similar virulence factors possessed by SDSE and S. pyogenes, both microorganisms show similar pathogenicity. The SDSE can be isolated as normal flora of human skin, nasopharynx, digestive tract and genitourinary system [10, 19, 27]. Pharyngeal [12, 33, 47-49] and nasal [31] carrier-state of that pathogen has been reported. The frequency of pharyngeal carrier-state is different in particular populations. Zaoutis et al. [50] discovered SDSE in 1.5\% of American children aged 6-13 (average of 10 years). Steer et al. found SDSE in 18.9\% of children in a group aged 5-14 in Fiji [49]. McDonald et al. discovered pharyngeal carrier-state in $5 \%$ of individuals in Australian Aboriginal communities [51], with 5.8\% in children under 15 years of age [52]. The latter work showed that pharyngeal SDSE carrier-state is most common between 5 and 14 years of age, exceeding 10\% [52].

The SDSE may cause toxic shock syndrome $[2,4,12$, $17,19,22,23,31,32,34,35,42,53,54]$ and other invasive infections, such as bacteremia without identified focus (primary bacteremia) [4, 19, 30, 32, 34, 55, 56], meningitis [4, 19, 34, 56, 57], pneumonia [3, 4, 19, 30, 34, 56-58], peritonitis [4, 22], sepsis $[2,16,17,31,57,58]$ including urosepsis [3], osteomyelitis [4, 19, 34, 57], including spondylodiscitis [59], arthritis [2-4, 19, 30, 34, 57, 58, 60], necrotizing fasciitis $[2,4,12,19,32,34,41]$, cellulitis [2-4, 17, 19, 29-31, 33, 34, 41, 54, 55, 57, 61], including erysipelas [11, 16, 62], patellar bursitis [57], appendicitis [4], salpingitis [22], abscesses of various locations [4, 19, 30, 34], endocarditis [4, 19, 30, 34, 56, 57], pyomyositis [21], gas gangrene [29, 63], diabetic gangrene [12], and cystitis [31]. The SDSE may also cause non-invasive infections: cutaneous (impetigo $[47,48]$ ) and mucous (tonsillopharyngitis [2, 7, 20, 25, 31, 53, 64], otitis media [2, 40]). Sporadically, infections caused by SDSE are followed by acute glomerulonephritis [65-67]. There is also a growing number of evidence for the connection between SDSE and rheumatic fever [46, 68].

The portal of entry for SDSE may be venous ulcers of legs [59]. Some works reported recurrent bacteremia induced by SDSE [55]. There is a description of toxic shock syndrome in a neonate that took place $12 \mathrm{~h}$ after birth and was caused by a strain having the same emm type and PFGE pattern as the maternal one, which suggests a possibility of SDSE carrier-state in pregnant women and vertical transmission of the microorganism to a newborn, as in the case of S. agalactiae [53]. Three cases of iatrogenic SDSE infection following transfusion of platelet concentrates were described [19], as well as cases of nosocomial infections [30]. It was found that most patients with invasive infections caused by SDSE were suffering from additional disorders, especially with cardiovascular diseases of atherosclerotic etiology, diabetes, obesity, 
chronic disorders of soft tissues (diabetic foot, decubitus ulcers, chronic lymphedema, venous stasis), impaired renal or liver function, and malignant neoplasms [2-4, 30, 34, 57]. The SDSE infections occur in all age groups, but the frequency of invasive infections significantly increases after 50 years of age [2, 19, 30, 34], when the abovementioned risk factors are more common.

The SDSE, unlike S. pyogenes, has also been isolated from animals: horses [69-71], pigs [72, 73], dogs [74], camels [75], cattle [44] and sea otters [76]. Marked differences have been found between SDSE strains deriving from humans and animals [44, 73]. Kawata et al. [73] discovered no streptokinase activity on human plasminogen in any of 11 SDSE strains isolated from pigs, such activity being one of the most important distinctive features of this bacterium [1]. Due to lack of data, it is not yet certain whether animals participate in transmission of that microorganism to people [70]. The available literature gives no documented cases of zoonotic infections, in contrast with S. equi subsp. zooepidemicus, which is rather closely related [35] to SDSE [77].

\section{Antimicrobial susceptibility}

The SDSE strains remain susceptible to penicillin and other $\beta$-lactams $[2,4,10,19,23,25,30,57]$. Penicillin is the drug of choice in infections caused by that microorganism. One of recent works describes 2 isolates with minimal inhibitory concentration (MIC) for penicillin of $0.25 \mu \mathrm{g} / \mathrm{ml}$, in a group of 472 (1997-2004) $\beta$-hemolytic streptococci deriving from Europe and North America, possessing group $\mathrm{G}$ or $\mathrm{C}$ antigens [78], but there is no clear information on species identification of those two strains. This value ( $\mathrm{MIC}=0.25$ ) is a breakpoint, and it is still interpreted as "susceptibility" according to binding European Committee on Antimicrobial Susceptibility Testing (EUCAST) recommendations [79], while Clinical and Laboratory Standards Institute (CLSI) guidelines of 2011 [80] treat it as "non-susceptibility".

The SDSE, like S. pyogenes, may enter cells of pharyngeal mucous membrane cells and, as an intracellular pathogen, avoid penicillin or other $\beta$-lactams, which may be a reason for the described therapeutic failures [25]. In this connection, should a $\beta$-lactam be ineffective in therapy of SDSE-induced infections, a cell-penetrating antibiotic ought to be used, chosen according to the antimicrobial susceptibility test (preferably a macrolide, or, in the case of a macrolide-resistant strain, antibiotic of tetracycline or a new fluoroquinolone group, or clindamycin) $[25,64]$. In treatment of more serious infections, particularly those associated with toxic shock syndrome, a $\beta$-lactam should be administered together with clindamycin [10].

Investigations showed a different percentage of strains resistant to macrolides, lincosamides and streptogramins $B$ in SDSE. There are several phenotypes of resistance, which result from presence and expression of specific genes: mef(A) encodes an efflux pump that pumps out 14- and 15-membered macrolides, which results in resistance to these antibiotics ( $M$ phenotype); $\operatorname{erm}(A)$ and $\operatorname{erm}(B)$ encode ribosomal methylases which mediate resistance to macrolides, lincosamides and streptogramins B by the inducible (iMLS $\mathrm{B}_{B}$ phenotype) and constitutive mechanism ( $C M L S_{B}$ phenotype). $\mathrm{iMLS}_{B}$ and $C M L S_{B}$ phenotypes exclude use of macrolides, lincosamides and streptogramins $B$, while $M$ phenotype excludes treatment with 14- and 15-membered macrolides [81-83]. Zaoutis et al. stated that among 23 SDSE isolates, 3 (13.0\%) were resistant to erythromycin (1991-1996) [57]. Lopardo et al. discovered one isolate (3.7\%) having erm(TR), subclass erm(A), among 27 invasive SDSE isolates coming from Argentina (1998-1999) [17]. Woo et al. [30], in a group of 66 isolates (1997-2000), found two (3.0\%) resistant to erythromycin and clindamycin, and one (1.5\%) resistant to erythromycin and susceptible to clindamycin. Broyles et al. discovered resistance to erythromycin in $28.8 \%$, and to clindamycin in $4.2 \%$ of isolates coming from invasive infections in California and Georgia $(n=212)$, however giving no specification of types of resistance (2002-2004) [4]. Uh et al., in a group of 32 SDSE isolates, discovered 3 (9.4\%) erythromycin-resistant isolates. Each of them had a different phenotype of resistance $\left(M, i M L S_{B}, C M L S_{B}\right)$ (2003-2004) [84]. Hashikawa et al. detected ermB in one strain among 11 SDSE isolates which caused streptococcal toxic shock syndrome (9.1\%). The other ones were susceptible to erythromycin, clarithromycin and clindamycin [23]. Sunaoshi et al., in a group of invasive and non-invasive infection isolates in Japan $(n=145)$, detected mef $(A)$ in $4.8 \%, \operatorname{erm}(A)$ in $2.1 \%$, and erm $(B)$ in $3.4 \%$ of strains. In total, genes for resistance to macrolides were detected in 10.3\% of isolates (2003-2005) [2]. Takahashi et al. examined a group of isolates coming from invasive infections in Japan $(2006-2007)(n=231)$. mef $(A)$ was present in $1.7 \%$, erm $(A)$ in $5.6 \%$, and erm $(B)$ in $2.6 \%$ of isolates $[19,34]$.

Resistance to tetracyclines is very common, which excludes use of these antibiotics in the empirical therapy of infections caused by SDSE [10]. Lopardo et al. discovered (1998-1999) 40.7\% of strains resistant to tetracyclines [17]. All of them contained tet $(M)$ [17]. Broyles et al. (2002-2004) discovered that 58\% of isolates were intermediate to tetracycline [4]. Uh et al. (2003-2004) [84] discovered $68.8 \%$ of strains resistant to tetracycline. Hashikawa et al. detected tetM in two SDSE isolates (18.2\%) [23]. Liu et al. detected tetS in $6.4 \%(n=12)$ of 188 (1998-2004) SDSE isolates resistant to tetracycline [85]. Both these genes encode ribosomal protection proteins (RPP) that prevent binding the antibiotic to the ribosome, which allows protein synthesis (translation) [86].

Biedenbach et al. [78] detected the lowest inhibitory concentrations for levofloxacin $\geq 2 \mu \mathrm{g} / \mathrm{ml}$ in $2.9 \%(n=14)$ strains out of 472 (1997-2004) $\beta$-hemolytic streptococci deriving from Europe and North America, possessing group G or C antigens. All isolates with elevated levofloxacin MIC 
Table 1. Antimicrobial susceptibility of the tested isolate of Streptococcus dysgalactiae subsp. equisimilis

\begin{tabular}{lccc}
\hline Antimicrobial agent & Disc content & Zone diameter [mm] & Interpretation \\
\hline Penicillin & $10 \mathrm{IU}$ & 29 & $\mathrm{~S}$ \\
\hline Erythromycin & $15 \mu \mathrm{g}$ & 22 & $\mathrm{~S}$ \\
\hline Clindamycin & $2 \mu \mathrm{g}$ & 21 & $\mathrm{~S}$ \\
\hline Levofloxacin & $5 \mu \mathrm{g}$ & 18 & $\mathrm{~S}$ \\
\hline Tetracycline & $30 \mu \mathrm{g}$ & 14 & $\mathrm{R}$ \\
\hline
\end{tabular}

$S$ - susceptible, $R$ - resistant

values were identified as SDSE. With one exception, they had mutations of gyrA, which encodes one of gyrase subunits, of parC encoding one of topoisomerase subunits, or of both genes. Some of them exhibited also resistance to moxifloxacin and gatifloxacin. Broyles et al. (2002-2004) observed resistance to fluoroquinolones in 2 isolates (0.9\%) [4]. Sunaoshi et al. (2003-2005) noted a high degree of resistance to levofloxacin (with MICs of $\geq 32 \mu \mathrm{g} / \mathrm{ml}$ ) in $2.8 \%$ of isolates, which was due to a mutation of gyrA and parC [2]. A markedly higher percentage of strains resistant to levofloxacin $(12.1 \%(n=38))$ was found among 314 $\beta$-hemolytic strains, forming large colonies (> $0.5 \mathrm{~mm}$ in diameter), possessing group $\mathrm{C}$ or $\mathrm{G}$ antigens, deriving from invasive and non-invasive infections from Portugal (19982005). In that work, a time-related increase of resistant strains was noted, from $11.4 \%$ in 2003 to $20.2 \%$ in 2005 [45]. Takahashi et al. (2006-2007) [19, 34] discovered a high degree of resistance to levofloxacin (the MICs of $\geq 32 \mu \mathrm{g} / \mathrm{ml}$ ) in $0.9 \%$ of isolates, which was due to a mutation of gyrA and parC. Hashikawa et al. reported all isolates to be susceptible to levofloxacin [23].

In 3 investigations where SDSE susceptibility to vancomycin was tested, all isolates were found to be susceptible to the antibiotic $[23,30,57]$. In one of these works [57], a part of the isolates exhibited tolerance to it (Minimal Bactericidal Concentration, MBC being 32 times or more higher than MIC).

Hashikawa et al. noted that all isolates were susceptible to trimethoprim-sulfamethoxazole, chloramphenicol and rifampicin (with rifampicin MIC $\leq 1.0 \mu \mathrm{g} / \mathrm{ml}$ ) [23]. Uh et al. discovered resistance to chloramphenicol in $9.4 \%$ of SDSE isolates [84].

In the work of Lopardo et al., one SDSE isolate was found to produce the bifunctional enzyme (AAC(6')APH(2")) mediating high-degree resistance to gentamicin [17].

\section{Case report}

A 30-year-old white man, with moderate obesity and interdigital tinea pedis, presented with a relapse of infection of soft tissue in the left lower limb. Over 2 years preceding the infection, the patient experienced two episodes of erysipelas of the left crus, with redness, ede- ma, pain, immobility and fever. He received topical and general antibiotic treatment, with a positive result. The patient did not suffer from diabetes, vascular diseases or immune disorders. The bacterial strain isolated from erythematous, suppurative skin lesions on the left foot, when cultured in sheep blood agar, after $24 \mathrm{~h}$ of incubation in $\mathrm{CO}_{2}$ enriched atmosphere, formed grayish colonies, about $1 \mathrm{~mm}$ in diameter, surrounded by $\beta$-hemolysis zone, about $3 \mathrm{~mm}$ in diameter. Microscopic examination of the Gram-stained preparation revealed presence of Gram-positive cocci forming short chains and small clusters. The strain did not produce catalase. It had a group A antigen (Streptex, Remel, Lenexa, Kans., USA). It also did not produce L-pyrrolidonyl arylamidase (PYR 50 Test, Remel). Three identification tests, one for manual identification (API 20 Strep, bioMerieux, Marcy l'Etoile, France) and the other two for automatic identification (rapid ID 32 Strep, bioMerieux; VITEK 2 GP identification card, bioMerieux), basing on biochemical properties, allowed to identify the strain as Streptococcus dysgalactiae subsp. equisimilis (a number in the collection of the National Medicines Institute: 3932/09). Susceptibility of the isolate to several chosen antibiotics was tested using a disc diffusion method. The measurement of antimicrobial susceptibility and interpretation of the results were performed in accordance with the standards of the Clinical and Laboratory Standards Institute (2011) [80].

The results of antimicrobial susceptibility tests are presented in Table 1.

First-generation cephalosporin (cefadroxil) was used in the treatment, resulting in a complete remission of the infection symptoms. No events of relapse were noted during the next 12-month observation period.

\section{References}

1. Vandamme P, Pot B, Falsen E, et al. Taxonomic study of Lancefield streptococcal groups C, G, and L (Streptococcus dysgalactiae) and proposal of $\mathrm{S}$. dysgalactiae subsp. equisimilis subsp. nov. Int J Syst Bacteriol 1996; 46: 774-81.

2. Sunaoshi K, Murayama SY, Adachi K, et al. Molecular emm genotyping and antibiotic susceptibility of Streptococcus dysgalactiae subsp. equisimilis isolated from invasive and non-invasive infections. J Med Microbiol 2010; 59: 82-8. 
3. Takahashi T, Asami R, Tanabe K, et al. Clinical aspects of invasive infection with Streptococcus dysgalactiae subsp. equisimilis in elderly patients. J Infect Chemother 2010; 16: 68-71.

4. Broyles LN, Van Beneden C, Beall B, et al. Population-based study of invasive disease due to beta-hemolytic streptococci of groups other than A and B. Clin Infect Dis 2009; 48: 706-12.

5. Reissmann S, Friedrichs C, Rajkumari R, et al. Contribution of Streptococcus anginosus to infections caused by groups C and G streptococci, southern India. Emerg Infect Dis 2010; 16: 656-63.

6. McMillan DJ, Bessen DE, Pinho M, et al. Population genetics of Streptococcus dysgalactiae subspecies equisimilis reveals widely dispersed clones and extensive recombination. PLoS One 2010; 5: e11741.

7. Pinho MD, Melo-Cristino J, Ramirez M. Clonal relationships between invasive and noninvasive Lancefield group $C$ and $G$ streptococci and emm-specific differences in invasiveness. J Clin Microbiol 2006; 44: 841-6.

8. Ahmad Y, Gertz RE Jr, Li Z, et al. Genetic relationships deduced from emm and multilocus sequence typing of invasive Streptococcus dysgalactiae subsp. equisimilis and S. canis recovered from isolates collected in the United States. J Clin Microbiol 2009; 47: 2046-54.

9. Facklam R. What happened to the streptococci: overview of taxonomic and nomenclature changes. Clin Microbiol Rev 2002; 15: 613-30.

10. Brandt CM, Spellerberg B. Human infections due to Streptococcus dysgalactiae subspecies equisimilis. Clin Infect Dis 2009; 49: 766-72.

11. Bert F, Lambert-Zechovsky N. Analysis of a case of recurrent bacteraemia due to group A Streptococcus equisimilis by pulsed-field gel electrophoresis. Infection 1997; 25: 250-1.

12. Tanaka D, Isobe J, Watahiki M, et al. Genetic features of clinical isolates of Streptococcus dysgalactiae subsp. equisimilis possessing Lancefield's group A antigen. J Clin Microbiol 2008; 46: 1526-9

13. Katsukawa C, Tamaru A, Morikawa Y. Streptococcus dysgalactiae subsp. equisimilis possessing Lancefield's group A anti gen. Kansenshogaku Zasshi 2002; 76: 155-60.

14. Mitsuno N, Hari T, Tamagawa N, et al. Evaluation of rapid diagnostic kits for the detection of group A streptococcus to Streptococcus pyogenes and Streptococcus spp. with Lancefield's group A antigen. Kansenshogaku Zasshi 2006; 80: 665-73.

15. McMillan DJ, Vu T, Bramhachari PV, et al. Molecular markers for discriminating Streptococcus pyogenes and S. dysgalactiae subspecies equisimilis. Eur J Clin Microbiol Infect Dis 2010; 29: 585-9.

16. Brandt CM, Haase G, Schnitzler N, et al. Characterization of blood culture isolates of Streptococcus dysgalactiae subsp. equisimilis possessing Lancefield's group A antigen. J Clin Microbiol 1999; 37: 4194-7.

17. Lopardo HA, Vidal P, Sparo M, et al. Six-month multicenter study on invasive infections due to Streptococcus pyogenes and Streptococcus dysgalactiae subsp. equisimilis in Argentina. J Clin Microbiol 2005; 43: 802-7.

18. http://www.cdc.gov/ncidod/biotech/strep/strep-doc/ index.htm

19. Takahashi T, Ubukata K, Watanabe H. Invasive infection caused by Streptococcus dysgalactiae subsp. equisimilis: characteristics of strains and clinical features. J Infect Chemother 2011; 17: 1-10.
20. Dierksen KP, Tagg JR. Haemolysin-deficient variants of Streptococcus pyogenes and S. dysgalactiae subsp. equisimilis may be overlooked as aetiological agents of pharyngitis. J Med Microbiol 2000; 49: 811-6.

21. Woo PC, Teng J, Lau SK, et al. Analysis of a viridans group strain reveals a case of bacteremia due to Lancefield group $\mathrm{G}$ alpha-hemolytic Streptococcus dysgalactiae subsp. equisimilis in a patient with pyomyositis and reactive arthritis. J Clin Microbiol 2003; 41: 613-8.

22. Horii T, Izumida S, Takeuchi K, et al. Acute peritonitis and salpingitis associated with streptococcal toxic shock syndrome caused by Lancefield group G alpha-haemolytic Streptococcus dysgalactiae subsp. equisimilis. J Med Microbiol 2006; 55: 953-6.

23. Hashikawa S, linuma Y, Furushita M, et al. Characterization of group $C$ and $G$ streptococcal strains that cause streptococcal toxic shock syndrome. J Clin Microbiol 2004; 42: 186-92.

24. Davies MR, McMillan DJ, Beiko RG, et al. Virulence profiling of Streptococcus dysgalactiae subspecies equisimilis isolated from infected humans reveals 2 distinct genetic lineages that do not segregate with their phenotypes or propensity to cause diseases. Clin Infect Dis 2007; 44: 1442-54.

25. Savini V, Catavitello C, Talia M, et al. Beta-lactam failure in treatment of two group $G$ Streptococcus dysgalactiae subsp. equisimilis pharyngitis patients. J Clin Microbiol 2008; 46: 814-6.

26. Rekomendacje postępowania w pozaszpitalnych zakażeniach układu oddechowego 2010. Narodowy Program Ochrony Antybiotyków.

27. Vieira VV, Teixeira LM, Zahner V, et al. Genetic relationships among the different phenotypes of Streptococcus dysgalactiae strains. Int J Syst Bacteriol 1998; 48: 1231-43.

28. Liu LC, Tsai JC, Hsueh PR, et al. Rapid differentiation between members of the anginosus group and Streptococcus dysgalactiae subsp. equisimilis within beta-hemolytic group C and G streptococci by PCR. J Clin Microbiol 2006; 44: 1836-8.

29. Sing A, Trebesius K, Heesemann J. Diagnosis of Streptococcus dysgalactiae subspecies equisimilis (Group C streptococci) associated with deep soft tissue infections using fluorescent in situ hybridization. Eur J Clin Microbiol Infect Dis 2001; 20: 146-9.

30. Woo PC, Fung AM, Lau SK, et al. Group G beta-hemolytic streptococcal bacteremia characterized by $16 \mathrm{~S}$ ribosomal RNA gene sequencing. J Clin Microbiol 2001; 39: 3147-55.

31. Minami M, Ichikawa M, Matsui $\mathrm{H}$, et al. Prevalence of a streptococcal inhibitor of a complement-mediated cell lysis-like gene (sicG) in Streptococcus dysgalactiae subsp. equisimilis. Curr Microbiol 2011; 62: 884-7.

32. Kittang BR, Skrede S, Langeland N, et al. emm gene diversity, superantigen gene profiles and presence of SlaA among clinical isolates of group A, C and G streptococci from western Norway. Eur J Clin Microbiol Infect Dis 2011; 30: 423-33.

33. Siljander T, Karppelin M, Vähäkuopus S, et al. Acute bacterial, nonnecrotizing cellulitis in Finland: microbiological findings. Clin Infect Dis 2008; 46: 855-61.

34. Takahashi T, Sunaoshi K, Sunakawa K, et al. Clinical aspects of invasive infections with Streptococcus dysgalactiae ssp. equisimilis in Japan: differences with respect to Streptococcus pyogenes and Streptococcus agalactiae infections. Clin Microbiol Infect 2010; 16: 1097-103.

35. Shimomura Y, Okumura K, Murayama SY, et al. Complete genome sequencing and analysis of a Lancefield group $G$ Streptococcus dysgalactiae subsp. equisimilis strain causing 
streptococcal toxic shock syndrome (STSS) BMC Genomics 2011; $12: 17$.

36. Suzuki H, Lefebure T, Hubisz MJ, et al. Comparative genomic analysis of the Streptococcus dysgalactiae species group: gene content, molecular adaptation, and promoter evolution. Genome Biol Evol 2011; 3: 168-85.

37. Woo PC, Teng JL, Wu JK, et al. Guidelines for interpretation of $16 \mathrm{~S}$ rRNA gene sequence-based results for identification of medically important aerobic Gram-positive bacteria. J Med Microbiol 2009; 58: 1030-6.

38. Igwe El, Shewmaker PL, Facklam RR, et al. Identification of superantigen genes speM, ssa, and smeZ in invasive strains of beta-hemolytic group $\mathrm{C}$ and $\mathrm{G}$ streptococci recovered from humans. FEMS Microbiol Lett 2003; 229: 259-64.

39. Hashikawa S, linuma Y, Furushita $M$, et al. Characterization of group $C$ and $G$ streptococcal strains that cause streptococcal toxic shock syndrome. J Clin Microbiol 2004; 42: 186-92.

40. Sachse S, Seidel P, Gerlach D, et al. Superantigen-like gene(s) in human pathogenic Streptococcus dysgalactiae, subsp equisimilis: genomic localisation of the gene encoding streptococcal pyrogenic exotoxin G (speGdys). FEMS Immunol Med Microbiol 2002; 34: 159-67.

41. Kittang BR, Langeland N, Skrede S, et al. Two unusual cases of severe soft tissue infection caused by Streptococcus dysgalactiae subsp. equisimilis. J Clin Microbiol 2010; 48: 1484-7.

42. Ikebe T, Murayama S, Saitoh K, et al. Surveillance of severe invasive group-G streptococcal infections and molecular typing of the isolates in Japan. Epidemiol Infect 2004; 132: 145-9.

43. Kalia A, Bessen DE. Presence of streptococcal pyrogenic exotoxin $A$ and $C$ genes in human isolates of group $G$ streptococci. FEMS Microbiol Lett 2003; 219: 291-5.

44. Zhao J, Hayashi T, Saarinen S, et al. Cloning, expression, and characterization of the superantigen streptococcal pyrogenic exotoxin G from Streptococcus dysgalactiae. Infect Immun 2007; 75: 1721-9.

45. Pinho MD, Melo-Cristino J, Ramirez M. Fluoroquinolone resistance in Streptococcus dysgalactiae subsp. equisimilis and evidence for a shared global gene pool with Streptococcus pyogenes. Antimicrob Agents Chemother 2010; 54: 1769-77.

46. Davies MR, Tran TN, McMillan DJ, et al. Inter-species genetic movement may blur the epidemiology of streptococcal diseases in endemic regions. Microbes Infect 2005; 7: 1128-38.

47. McDonald M, Towers RJ, Andrews RM, et al. Epidemiology of Streptococcus dysgalactiae subsp. equisimilis in tropical communities, Northern Australia. Emerg Infect Dis 2007; 13: 1694-700.

48. Steer AC, Magor G, Jenney AW, et al. emm and C-repeat region molecular typing of beta-hemolytic streptococci in a tropical country: implications for vaccine development. J Clin Microbiol 2009; 47: 2502-9.

49. Steer AC, Jenney AW, Kado J, et al. Prospective surveillance of streptococcal sore throat in a tropical country. Pediatr Infect Dis J 2009; 28: 477-82.

50. Zaoutis T, Attia M, Gross R, et al. The role of group C and group $\mathrm{G}$ streptococci in acute pharyngitis in children. Clin Microbiol Infect 2004; 10: 37-40.

51. McDonald M, Towers R, Fagan P, et al. Recovering streptococci from the throat, a practical alternative to direct plating in remote tropical communities. J Clin Microbiol 2006; 44: 547-52.
52. McDonald MI, Towers RJ, Andrews RM, et al. Low rates of streptococcal pharyngitis and high rates of pyoderma in Australian aboriginal communities where acute rheumatic fever is hyperendemic. Clin Infect Dis 2006; 43: 683-9.

53. Yamaoka S, Ogihara T, Yasui M, et al. Neonatal streptococcal toxic shock syndrome caused by Streptococcus dysgalactiae subsp. equisimilis. Pediatr Infect Dis J 2010; 29: 979-81.

54. Misawa Y, Okugawa S, Ubukata K, et al. A case of severe necrotizing cellulitis caused by group $\mathrm{G}$ Streptococcus dysgalactiae subsp. equisimilis. Kansenshogaku Zasshi 2006; 80: 436-9.

55. Liao CH, Liu LC, Huang YT, et al. Bacteremia caused by group G streptococci, Taiwan. Emerg Infect Dis 2008; 14: 837-40.

56. Steer AC, Jenney A, Kado J, et al. Prospective surveillance of invasive group a streptococcal disease, Fiji, 2005-2007. Emerg Infect Dis 2009; 15: 216-22.

57. Zaoutis T, Schneider B, Steele Moore L, et al. Antibiotic susceptibilities of group $C$ and group $G$ streptococci isolated from patients with invasive infections: evidence of vancomycin tolerance among group $\mathrm{G}$ serotypes. J Clin Microbiol 1999; 37: 3380-3.

58. Steer AC, Jenney AJ, Oppedisano F, et al. High burden of invasive beta-haemolytic streptococcal infections in Fiji. Epidemiol Infect 2008; 136: 621-7.

59. Lestin F, Mann S, Podbielski A. Spondylodiscitis and paraspinal abscess caused by beta-haemolytic group $\mathrm{G}$ streptococci spreading from infected leg ulcers. J Med Microbiol 2008; 57: 1157-60.

60. Moser C, Andresen K, Kjerulf A, et al. Infective arthritis: bacterial 235 rRNA gene sequencing as a supplementary diagnostic method. Open Microbiol J 2008; 2: 85-8.

61. Hilmarsdóttir I, Valsdóttir F. Molecular typing of beta-hemolytic streptococci from two patients with lower-limb cellulitis: identical isolates from toe web and blood specimens. J Clin Microbiol 2007; 45: 3131-2.

62. Bomke AK, Vagts DA, Podbielski A. Toxic-shock-like-syndrome caused by beta-hemolysing group $\mathrm{G}$ streptococci in a multimorbid patient with erysipelas. Dtsch Med Wochenschr 2006; 131: 263-6.

63. Horibe M, Sano Y, Himeno T, et al. Case of gas gangrene in both legs due to Streptococcus dysgalactiae subsp. equisimilis, resulting in amputation of right leg. Nippon Naika Gakkai Zasshi 2008; 97: 1879-81.

64. Palmieri C, Rätsch IM, Princivalli MS, et al. erm(A)-mediated macrolide resistance and ability to invade human respiratory cells in a Streptococcus dysgalactiae subspecies equisimilis pharyngeal isolate. J Antimicrob Chemother 2007; 60: 1405-6.

65. Tewodros W, Muhe L, Daniel E, et al. A one-year study of streptococcal infections and their complications among Ethiopian children. Epidemiol Infect 1992; 109: 211-25.

66. Gnann JW Jr, Gray BM, Griffin FM Jr, et al. Acute glomerulonephritis following group $\mathrm{G}$ streptococcal infection. J Infect Dis 1987; 156: 411-2.

67. Reid HF, Bassett DC, Poon-King T, et al. Group G streptococ$\mathrm{Ci}$ in healthy school-children and in patients with glomerulonephritis in Trinidad. J Hyg (Lond) 1985; 94: 61-8.

68. Dinkla K, Nitsche-Schmitz DP, Barroso V, et al. Identification of a streptococcal octapeptide motif involved in acute rheumatic fever. J Biol Chem 2007; 282: 18686-93.

69. Timoney JF. The pathogenic equine streptococci. Vet Res 2004; 35: 397-409. 
70. Preziuso S, Laus F, Tejeda AR, et al. Detection of Streptococcus dysgalactiae subsp. equisimilis in equine nasopharyngeal swabs by PCR. J Vet Sci 2010; 11: 67-72.

71. Laus F, Preziuso S, Spaterna A, et al. Clinical and epidemiological investigation of chronic upper respiratory diseases caused by beta-haemolytic streptococci in horses. Comp Immunol Microbiol Infect Dis 2007; 30: 247-60.

72. Zoric M, Nilsson E, Lundeheim N, et al. Incidence of lameness and abrasions in piglets in identical farrowing pens with four different types of floor. Acta Vet Scand 2009; 51: 23.

73. Kawata K, Minakami T, Mori Y, et al. rDNA sequence analyses of Streptococcus dysgalactiae subsp. equisimilis isolates from pigs. Int J Syst Evol Microbiol 2003; 53: 1941-6.

74. Lamm CG, Ferguson AC, Lehenbauer TW, et al. Streptococcal infection in dogs: a retrospective study of 393 cases. Vet Pathol 2010; 47: 387-95.

75. Younan M, Bornstein S. Lancefield group B and C streptococc in East African camels (Camelus dromedarius). Vet Rec 2007; 160: 330-5.

76. Imai D, Jang S, Miller M, et al. Characterization of beta-hemolytic streptococci isolated from southern sea otters (Enhydra lutris nereis) stranded along the California coast. Vet Microbiol 2009; 136: 378-81.

77. Poulin MF, Boivin G. A case of disseminated infection caused by Streptococcus equi subspecies zooepidemicus. Can J Infect Dis Med Microbiol 2009; 20: 59-61.

78. Biedenbach DJ, Toleman MA, Walsh TR, et al. Characterization of fluoroquinolone-resistant beta-hemolytic Streptococcus spp. isolated in North America and Europe including the first report of fluoroquinolone-resistant Streptococcus dysgalactiae subspecies equisimilis: report from the SENTRY Antimicrobial Surveillance Program (1997-2004). Diagn Microbiol Infect Dis 2006; 55: 119-27.

79. http://www.korld.edu.pl/pdf/eucast/EUCAST_breakpoints 1-3popr.pdf

80. Clinical and Laboratory Standards Institute. 2011. Performance Standards for Antimicrobial Susceptibility Testing; Twenty-First Informational Supplement. CLSI document M100-S21. Clinical and Laboratory Standards Institute, Wayne, Pennsylvania.

81. Varaldo PE, Montanari MP, Giovanetti E. Genetic elements responsible for erythromycin resistance in streptococci. Antimicrob Agents Chemother 2009; 53: 343-53.

82. Leclercq R. Mechanisms of resistance to macrolides and lincosamides: nature of the resistance elements and their clinical implications. Clin Infect Dis 2002; 34: 482-92.

83. Żabicka D, Izdebski R, Hryniewicz W. Oznaczanie wrażliwości ziarniaków Gram-dodatnich z rodzaju Streptococcus spp. In: Rekomendacje doboru testów do oznaczania wrażliwości bakterii na antybiotyki i chemioterapeutyki 2009.

84. Uh Y, Hwang GY, Jang IH, et al. Macrolide resistance trends in beta-hemolytic streptococci in a tertiary Korean hospital. Yonsei Med J 2007; 48: 773-8.

85. Liu LC, Tsai JC, Hsueh PR, et al. Identification of tet(S) gene area in tetracycline-resistant Streptococcus dysgalactiae subsp. equisimilis clinical isolates. J Antimicrob Chemother 2008; 61: 453-5.

86. Thaker M, Spanogiannopoulos P, Wright GD. The tetracycline resistome. Cell Mol Life Sci 2010; 67: 419-31. 